\title{
Basic Food Safety Practise of Open-Air-Market Vending in the Eastern Highlands of Papua New Guinea
}

\author{
Johnson Makaen ${ }^{1 *}$, Tobias Maure ${ }^{1}$ and Sauli Bebes ${ }^{1}$ \\ ${ }^{1}$ Papua New Guinea Institute of Medical Research, Goroka EHP. \\ ${ }^{\star}$ Corresponding author: Johnson Makaen, Papua New Guinea Institute of Medical Research, Goroka EHP, E-mail: jmakaen@gmail.com
}

Received: March 10, 2017; Accepted: March 30, 2017; Published: April 28, 2017;

\begin{abstract}
A cross-sectional survey was conducted to appraise basic food safety practises by street or open-air market vendors about the township of Goroka in late 2014. Study subjects were randomly selected over a period of two months. Of the one hundred and twenty food vendors observed in the survey, most had unconventional methods of handling food or allowed consumers to pick up food with bare hands if they choose. Use of gloves was hardly observed. Only thirty-two percent handled cooked food with thongs or fork which was apparent at barbeque sites. Twenty-one percent of the subjects in the survey did not provide proper food wrappers. Water use was limited to fresh fruit sale but obviously lacking in all others. Practically all cooked-food vendors did not use covers on food containers consequently increasing the risk of environmental or fly contamination. This survey clearly demonstrates that street food vendors either possess limited knowledge of food safety and hygiene, or just improvise to earn a living. The activity is widespread and unregulated. However, such practise can easily set the stage for an outbreak of food-borne infection. Vulnerable consumers could be at particular risk and the practise could also help maintain and spread existing infections.
\end{abstract}

Key Words: Street food safety, sanitation, street food, vending and Papua New Guinea

\section{Background}

Easy access to clean water and proper sanitation relates to better health as much they are essential preconditions for promoting basic food safety [1-4]. Maintenance of hand hygiene through washing and use of gloves can lessen the level of contamination thereby ensuring food safety [4-7]. Contamination can occur during handling, processing or storage but can be minimised if appropriate safety measures are observed and those involved have a clear knowledge of basic food safety practises [8-10]. Some studies have found that the level of food contamination is associated with hygiene awareness and the attitudes of people involved in the business [11-13]. Contamination risk is nevertheless heightened if there is a notable gap in basic food safety knowledge and practise. $[1,3]$. In Papua New Guinea, most diarrhoeal infections originate from contaminated food or water subsequent to poor sanitation or inaccessibility to clean water [14]. Cooked food sale in the open environment in the highlands is common. It is an informal sector practised by locals including the unemployed. Food such as cooked vegetables, meat, rice or floor is often prepared at homes and brought to the vending site. The food is usually packed in large bowls, or cooking pots and transported to vending site as opposed to static food warmers used in restaurants or other established outlets where a certain level of food safety is assured. Ready-to-eat food sale in openair-market or street could be possibly compromised if there is a lax in food safety during preparation or storage for the duration of vending $[15,16]$. On the other hand, vendors may not be obliged to adhere to basic food safety measures as the activity is not regulated $[17,18]$.
This survey aims to identify key gaps in basic food safety practise with respect to handling, protection from environmental contamination and easy access to clean water.

\section{Materials and methods}

A cross-sectional survey was conducted in late 2014. It involved observing and recording the sale of ready-to-eat food, particularly cooked food by open-air-market or street vendor about the township of Goroka in the eastern highlands of Papua New Guinea. Sample size determination was not necessary as target subjects were limited and variable at the different sites visited. Data was obtained by observing key questions in a brief questionnaire without having to making verbal contact or interviewing subjects involved in the cooked-food sale. The anonymous approach by this this survey guaranteed confidential use of data. Questions were rather basic with the assumption that most of the vendors would possess basic concepts of hygiene and food safety despite having no formal training on food safety. Different sites were visited including the main market in town where such activities are competitive and frequent. Each questionnaire was completed through up-close examination of food containers, covers used on containers, serving utensils such as thongs, food wrapping and use of gloves. Observations were done on different occasions but it is possible some subjects may have appeared more than once in the survey as cooked food sale is common in the area. Necessary details of the vending events were captured in the questionnaire and analysed using Ms Excel. 


\section{Results}

Following the survey, majority of the street and open-air-market vendors failed to maintain basic food safety. Categories of food observed in the survey were basically local, cooked food (Table 1). The hundred and twenty $(n=120)$ vendors observed apparently demonstrated a low level of hygiene or food safety practise. Glove use $(0 \%)$ was not observed through the entire duration of the survey although most vendors applied irregular measures of food handling (32\%). It is probable that such food were prepared in similar manner and transported. Food wrapping (21\%) appeared to be improvised in some instances where old newspapers were used. On the other hand, local consumers had a tendency to pick up food with bare hand or simply choose to eat despite the obvious. Hygiene about the vending sites was questionable as running water or basic sanitation infrastructure was non-existent with periodic waste management. It is a widely known concept that hand hygiene is maintained through washing particularly during food preparation. However, water use was only observed in peeled, fresh-fruit sale (31\%). Virtually all food containers or boxes had covers stripped off (16\%) purposely to allow visibility of food to prospective consumers. This practise exposed food to environmental or fly contamination. In contrast to barbeques, most other cooked food sale did not maintain heat so evidently food went cold after a while. The practise appeared to be regular throughout the duration of the survey with similar method of food preparation. All measures undertaken by vendors to ensure food safety were documented (Figure 1).

Table1. Types of ready-to-eat food sold at streets or open-air-markets.

\begin{tabular}{|l|}
\hline Types of ready-to-eat food \\
\hline Barbeques (sausages, pork, lamb etc,.) \\
\hline Deep fried floor balls \\
\hline Fried potatoes \\
\hline Peeled fresh fruits \\
\hline Plain bread balls/sandwiches \\
\hline Boiled vegetables \\
\hline Fried eggs \\
\hline
\end{tabular}

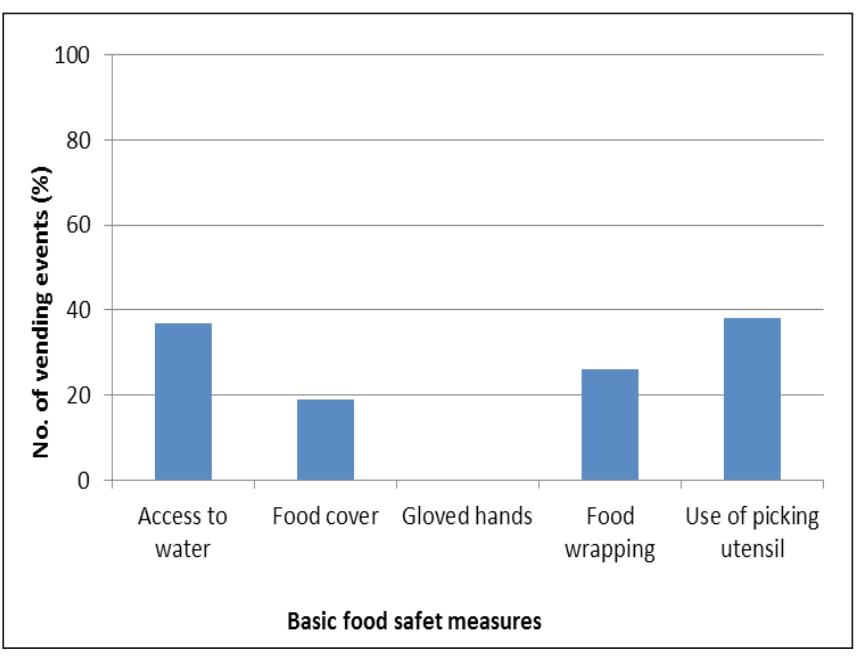

Figure 1. Observed food safety measures

\section{Discussion}

Sale and consumption of ready-to-eat food in streets or openair-markets in the highlands of Papua New Guinea is common amongst locals simply because they are within a consumer's means and convenient than restaurants or established fast-food outlets [16]. However, open-markets are makeshift and mobile, therefore lack the necessary structure to protect and maintain food safety [17]. Poor regulation of the practise and overall insanitary conditions of the environment and vending sites raises serious issues of both health and food safety [18]. The apparent lack of water and sanitation infrastructure at designated markets should be also be a concern for overall public health safety $[13,18]$. It was evident that individuals involved in this trade were semi-educated and possessed limited knowledge of basic food safety or would have had partial exposure to such information including personal hygiene [15]. The activity cannot be banned as it is an income-generating for many locals and unemployed town residents. The consistent demand for these easily accessible and cheap foods will certainly encourage and sustain the trade. This survey emphasizes the need to develop street-food safety by initiating awareness and education on basic food safety and raises the need to formulate appropriate codes of practise in accordance with the Hazard Analysis Critical Control Point (HACCP) guidelines [19, 20]. Moreover, public health authorities could consider developing policies aimed at training and registering or licensing street-food vending.

\section{Conclusion}

This survey clearly demonstrates that there is a poor level of food safety observance by vendors and consumer alike. In a region where diarrhoeal diseases are endemic and sanitation is deplorable, such vending practise has the potential to trigger enteric disease outbreaks $[14,21]$. However, these vending practises are likely to continue unhindered unless relevant authorities step up. Contamination of food is likely and can easily set the stage for an outbreak of foodborne infection or associated diarrhoeal illness particularly amongst the vulnerable populations [13]. In addition, the practise could also help maintain and spread existing infections. Further study is required to determine the extent of microbial contamination on food samples and hands of food handlers in the open-air-market vending business. A major limitation to this study is the obvious lack of a structured interview to establish individual knowledge of food safety and use of raw materials for food preparation.

\section{References}

1. Fewtrell L, et al. (2005) Water, sanitation, and hygiene interventions to reduce diarrhoea in less developed countries: a systematic review and meta-analysis. The Lancet Infectious Diseases 5:42-52.

2. Annette Prüss, D.K., Lorna Fewtrell, and Jamie Bartram, Estimating the Burden of Disease from Water, Sanitation, and Hygiene at a Global Level. Environmental Health Perspectives 110: 6.

3. Bartram J, Cairncross S (2010) Hygiene, sanitation, and water: forgotten foundations of health. PLoS Med 7: e1000367. [crossref]

4. Curtis V, Schmidt W, Luby S, Florez R, Touré O, et al. (2011) Hygiene: new hopes, new horizons. Lancet Infect Dis 11: 312-321. [crossref]

5. Ayçiçek H, et al. (2004) Assessment of the bacterial contamination on hands of hospital food handlers. Food Control 15: 4253-259.

6. Malhotra R, et al. (2006) Study of hand hygiene and enteroparasite infestation among food handlers working in a medical college of North India. Indian Journal of Pathology \& Microbiology 49: 296-301. 
7. Green LRR, Vincent Mason, Ryan Bushnell, Lisa Reimann, David W, Mack James C (2007) Motsinger, Michelle D.; Stigger, Tammi; Selman, Carol A., Factors Related to Food Worker Hand Hygiene Practices. Journal of Food Protection 6.

8. Lues JFR and I Van Tonder (2007) The occurrence of indicator bacteria on hands and aprons of food handlers in the delicatessen sections of a retail group. Food Control 18:326-332.

9. Brown KL and S Wray (2014) Control of airborne contamination in food processing in Hygiene in Food Processing (Second edition), HLM Lelieveld, Holah JT, and Napper D, Editors, Woodhead Publishing.174-202

10. Skovgaard N (2007) New trends in emerging pathogens. Int J Food Microbiol 120: 217-224. [crossref]

11. Angelillo IF, Viggiani NM, Rizzo L, Bianco A (2000) Food handlers and foodborne diseases: knowledge, attitudes, and reported behavior in Italy. J Food Prot 63 : 381-385. [crossref]

12. Bas M, Azmi Safak Ersun and Kivanç G (2006) The evaluation of food hygiene knowledge, attitudes, and practices of food handlers' in food businesses in Turkey. Food Control 17:5.

13. Isara AR, Isah EC, Lofor PV, Ojide CK (2010) Food contamination in fast food restaurants in Benin City, Edo State, Nigeria: Implications for food hygiene and safety. Public Health 124: 467-471. [crossref]
14. Horwood P, Greenhill A (2012) Cholera in Papua New Guinea and the importance of safe water sources and sanitation. Western Pac Surveill Response J 3: 3-5. [crossref]

15. FAO (2014) Food for the Cities: Food processing and street foods.

16. FAO (2014) Food for the Cities: Street Foods, 2014.

17. Chander Pal Thakur, Chahat Narula RM, Swati Mahapatra and Kalita TJ (2013) Food safety and hygiene practices among street food vendors in Delhi, India. International Journal of Current Research 5.

18. Regulators F.W.G.F.o.F.S (2002) The experience of improving the safety of street food via international technical assistance.

19. Ekanem EO (1998) The street food trade in Africa: safety and socio-environmental issues. Food Control 9: 211-215.

20. Unnevehr LJ and Jensen H (1999) The economic implications of using HACCP as a food safety regulatory standard. Food Policy 24: 625-635.

21. Bukenya, Nwokolo GB, Compound Hygiene N (1991) Presence of Standpipe and the Risk of Childhood Diarrhoea in an Urban Settlement of Papua New Guinea. International Journal of Epidemiology 20: 534-539.

Citation:

Johnson Makaen, Tobias Maure and Sauli Bebes (2017) Basic Food Safety Practise of Open-Air-Market Vending In The Eastern Highlands Of Papua New Guinea. Internal Med Res Open $J$ Volume 2(1): 1-3 